\title{
Preparation and application in HDPE of Nano-CaSO 4 from phosphogypsum
}

Shang Gonga ${ }^{\mathrm{a}}$, Xiaolong Lic ${ }^{\mathrm{c}}$, Fangxiang Songa ${ }^{\mathrm{a}}$, Dinghui $\mathrm{Lu}^{\mathrm{a}}$, Qianlin Chena, b,* ${ }^{a}$ School of Chemistry and Chemical Engineering, Guizhou University, Huaxi avenue, Huaxi district, Guiyang 550025, China ${ }^{b}$ National \& Local Joint Laboratory of Engineering for Effective Utilizati on of Regional Mineral Resources from Karst Areas, Guizhou University, Huaxi avenue, Huaxi district, Guiyang 550025, China

c. College of Materials and Metallurgy, Guizhou University, Huaxi avenue, Huaxi district, Guiyang 550025, China

* Corresponding authors, E-mail: cq11018@163.com (Q. -L. Chen).

The number of pages: 5

The number of figures: 2

The number of tables: 1 


\section{FT-IR analysis of conversion of PG into $\mathrm{Nano}_{-} \mathrm{CaSO}_{4}$}

To further confirm the transformation of PG into $\mathrm{Nano}_{-} \mathrm{CaSO}_{4}$, FT-IR spectroscopy was adopted to study the different interactions between crystallization water and calcium sulfate monocrystals, as shown in Fig. S1. Infrared spectral analysis shows that the characteristic peak (-OH) absorption bands of $\mathrm{H}_{2} \mathrm{O}$ appear between 3350 and $3550 \mathrm{~cm}^{-1}$ and between 1600 and $1700 \mathrm{~cm}^{-1}$, with peaks $(-\mathrm{OH})$ at $3547 \mathrm{~cm}^{-1}, 3404 \mathrm{~cm}^{-1}$, $1685 \mathrm{~cm}^{-1}$ and $1621 \mathrm{~cm}^{-1}$ corresponding to PG containing crystallization water, ${ }^{1-2}$ while the water peaks at these positions in $\mathrm{Nano}^{-\mathrm{CaSO}_{4}}$ basically disappear after treatment.

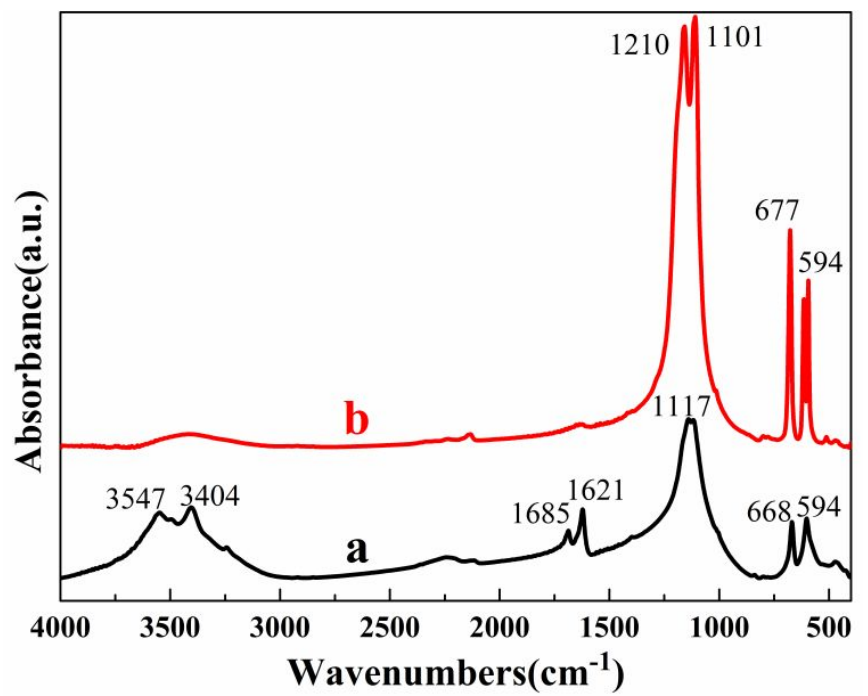

Fig. S1 FT-IR spectra of the PG transition to $\mathrm{Nano}_{-} \mathrm{CaSO}_{4}$ for (a) PG and (b) Nano-CaSO 4 .

In addition, the peaks between 1100 and $1210 \mathrm{~cm}^{-1}$ and between 590 and $700 \mathrm{~cm}^{-1}$ are $\mathrm{SO}_{4}{ }^{2-}$ absorption bands, the position between 1117 and $1101 \mathrm{~cm}^{-1}$ is the $v_{1} \mathrm{SO}_{4}{ }^{2-}$ symmetric stretching vibration peak, the peak at $1210 \mathrm{~cm}^{-1}$ is the $v_{3} \mathrm{SO}_{4}{ }^{2-}$ asymmetric stretching vibration peak, ${ }^{3}$ and the 
peaks at $677 \mathrm{~cm}^{-1}, 668 \mathrm{~cm}^{-1}$, and $594 \mathrm{~cm}^{-1}$ are the $v_{4} \mathrm{SO}_{4}{ }^{2-}$ asymmetric bending vibration peaks. ${ }^{4}$ According to the above analysis, PG mainly contains -OH and $\mathrm{SO}_{4}{ }^{2-}$ groups, and Nano-CaSO 4 mainly contains $\mathrm{SO}_{4}{ }^{2-}$ groups, which indicates that we have successfully synthesized Nano-CaSO .

\section{Crystallization properties of modified HDPE materials prepared}

\section{with $\mathrm{Nano}-\mathrm{CaSO}_{4}$}

Fig. S2 shows the crystallization and melting curves of pure HDPE and modified HDPE, and the corresponding crystallization and melting parameters are listed in Table S1.
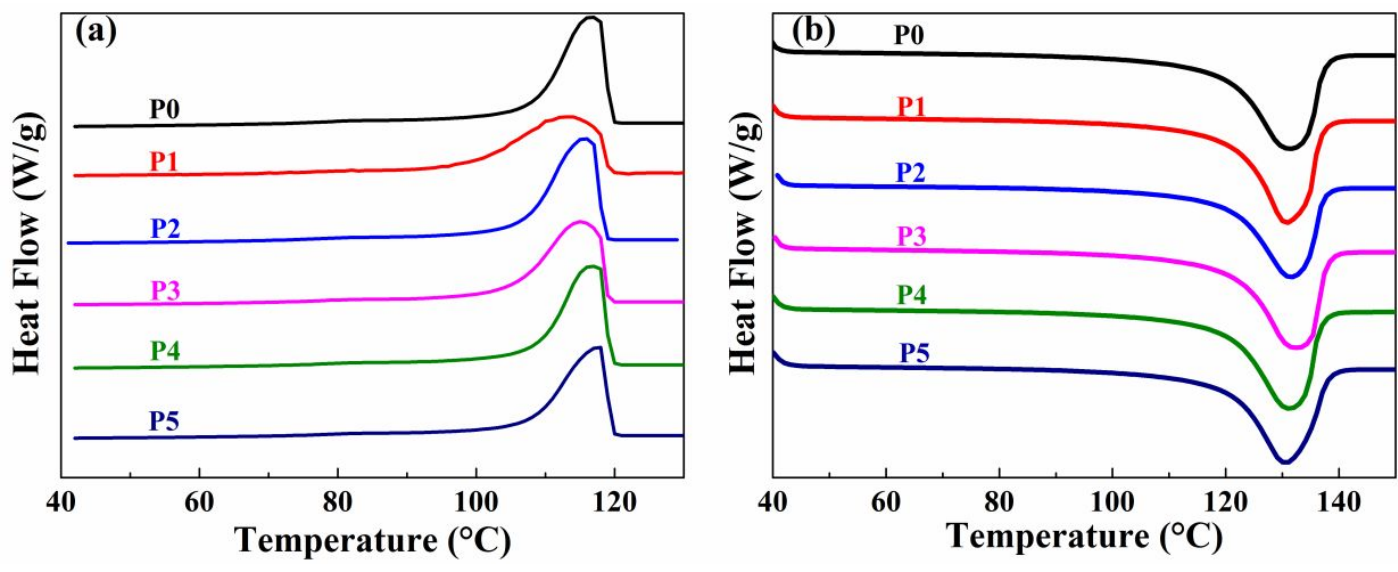

Fig. S2 Crystallization performance curve: (a) Cooling crystallization curve and (b) melting curve of secondary temperature increase.

The peak crystallization temperature of the material after adding PG ranges from $116.62{ }^{\circ} \mathrm{C}$ to $113.06{ }^{\circ} \mathrm{C}$ and $117.95{ }^{\circ} \mathrm{C}$, and when the content reaches $3 \mathrm{phr}$, this temperature is higher than the peak crystallization temperature of $131.53{ }^{\circ} \mathrm{C}$ of pure HDPE, indicating that a small amount 
of PG nucleates in the modified samples. When the content of Nano-CaSO${ }_{4}$ is less than $4 \mathrm{phr}, \mathrm{T}_{\mathrm{c}}$ decreases, and the crystallization peaks of the P1 and P3 samples widen, indicating that nucleation hysteresis occurs in the molecular chain. The chains freeze before they are fully aligned, leading to incomplete spherulite growth, and the crystals are destroyed at lower temperatures, thus widening the crystallization peaks. In addition, the melting temperature of the modified samples increases and then decreases, the melting peak widens, and the melting distance increases. The crystallinity of HDPE can be calculated according to the melting curve by using the following formula (1):

$X_{c}=\frac{\Delta H_{m}}{\Delta H_{m}^{0}} \times 100 \%$

where $\Delta \mathrm{H}_{\mathrm{m}}$ is the melting enthalpy of the sample, $\Delta \mathrm{H}_{\mathrm{m}}^{0}$ is the melting enthalpy of $100 \%$ crystalline $\mathrm{PE}\left(\Delta \mathrm{H}_{\mathrm{m}}^{0}=289 \mathrm{~J} / \mathrm{g}\right)$, and the crystallinities of HDPE and the modified samples calculated according to the above formula are listed in Table S1. The crystallinity of the modified samples is lower than that of pure HDPE because the presence of $\mathrm{Nano}^{-\mathrm{CaSO}_{4}}$ increases the entanglement between molecular chains, restricts the arrangement of molecular chains into the lattice, and reduces the regularity of chain segments.

Table S1 Relevant parameters obtained according to the DSC crystallization and melting curve. 


\begin{tabular}{ccccc}
\hline Sample & $\mathrm{T}_{\mathrm{cc}}\left({ }^{\circ} \mathrm{C}\right)$ & $\mathrm{T}_{\mathrm{m}}\left({ }^{\circ} \mathrm{C}\right)$ & $\Delta \mathrm{H}_{\mathrm{m}}(\mathrm{J} / \mathrm{g})$ & $\chi_{\mathrm{c}}$ \\
\hline P0 & 116.62 & 131.53 & 203.2 & 70.31 \\
P1 & 113.06 & 130.80 & 178.0 & 61.59 \\
P2 & 115.43 & 131.17 & 193.6 & 66.99 \\
P3 & 115.27 & 134.34 & 185.2 & 64.08 \\
P4 & 116.99 & 131.29 & 186.2 & 64.43 \\
P5 & 117.95 & 130.41 & 168.6 & 58.34 \\
\hline
\end{tabular}

\section{References}

(1) Tan, H.; Dong, F. Morphological regulation of calcium sulfate hemihydrate from phosphogypsum. Materialwiss. Werkst. 2017, 48, 1191-1196.

(2) Hazra, C.; Bari, S.; Kundu, D.; Chaudhari, A.; Mishra, S.; Chatterjee, A.

Ultrasound-assisted/biosurfactant-templated size-tunable synthesis of nano-calcium sulfate with controllable crystal morphology. Ultrason. Sonochem. 2014, 21, 1117-1131.

(3) Guan, Q. J.; Sun, W.; Hu, Y. H.; Yin, Z. G.; Guan, C. P. A facile method of transforming FGD gypsum to $\alpha-\mathrm{CaSO} 4 \cdot 0.5 \mathrm{H} 2 \mathrm{O}$ whiskers with cetyltrimethylammonium bromide (CTAB) and $\mathrm{KCl}$ in glycerol-water solution. $\mathrm{Sci}$. Rep-UK. 2017, 7, 7085.

(4) Zhao, W. P.; Wu Y. M.; Xu, J.; Gao, C. H. Effect of ethylene glycol on hydrothermal formation of calcium sulfate hemihydrate whiskers with high aspect ratios $R S C A d v . \mathbf{2 0 1 5}, 5,50544-50548$. 